\title{
Study of the behaviour of natural radionuclides in a Mediterranean actual system
}

\author{
A. Agüero and P. Pinedo \\ CIEMAT/DIAE, Avda. Complutense 22, 28040 Madrid, Spain
}

\begin{abstract}
There is a lack of information for Mediterranean climate conditions and ecosystems from the point of view of characterization of real data, to obtain parameter values to be applied in the modeling of the behavior of natural and artificial radionuclides following hypothetical releases from a radioactive waste repository. So there was designed a project dealing with the study and determination of physical, chemical and radiological parameters from local and regional data obtained in an atea of the southwest of Spain where and old uranium mine was being restored.

The project, running during two years, has been financed by the National Company for Radioactive Waste Management in Spain (ENRESA) and has been coordinated by the CIEMAT Research Center with the collaboration of the Department of Physics of the Extremadura University.

Results of the project have been the characterization of the biosphere system considering meteorological, geological, and hydrological data. Chemical and physical characterization of local soils and crops associated, surface waters and sediments samples, have been considered. Radiological measurements of $\mathrm{U}$, Th and $\mathrm{Ra}$ contents in soils, vegetables, sediments and waters have been taken.

Range of several parameter values obtained have shown good agreement with literature data published, this will permit the application of these values to the modeling issues of biosphere in the performance assessment of radioactive waste repositories under Mediterranean climate conditions, as well as for a forecasting of similar conditions that will occur in the future in other temperate areas.
\end{abstract}

\subsection{BJECTIVES}

Main objectives of the investigation have been to characterize the area, considering climatic and meteorological conditions, geological features, hydrogeology, soils development, ecological conditions and anthropological features. These are considered under Biosphere System Description. Determination of parameter values for the transfer of uranium isotopes in the biospheric area has been performed. The methodology followed to select isotopes, sample types and sample points and materials and methods used to obtain the data for determining parameter values is described afterwards. The last part of the paper reports on examples of experimental and empirical values obtained for solid-liquid distribution coefficients in soils and sediments of the biospheric area under study.

\section{BIOSPHERE SYSTEM DESCRIPTION}

The area has been characterised regionally, considering an area of $10 \mathrm{Km}$ of radius; and locally, considering an extension of $50 \mathrm{Km}^{2}$.

Regional climate is Temperate Mediterranean (naming type Cs) [1]. Mean precipitation in this case is in the range between 300 and $900 \mathrm{~mm}$ per year. There is a pronounced precipitation maximum during cooler months, summer being nearly if not absolutely dry. This feature of dry summers and wet winters classify the regional climate of the area as Mediterranean sub humid. Mean temperatures are in the range between 14 and 17 Celsius degrees. Real evapotranspiration obtained from local data is in the range between 470 and $490 \mathrm{~mm}$ per year.

Local geology is characterised by granites and shales. Altitudes are in the range between 400 and $500 \mathrm{~m}$ height. Groundwater flow, regionally, follows topographical features, mountains are the recharge zones and rivers and streams are the discharge zones. Local flows are over regional flows and constitute the hydrogeological systems of the soils developed over granites and altered surface granitic rocks.

Soils developed from granitic rocks, are classified as two types of Entisols following USDA, 1975 [2] classification, Typic Xerorthent with low depth of A horizon and B horizon absent. And Aeric Haplaquent, with an important contrast between its two horizons and high organic matter content in the surface soil. These are saturated part of the year.

Soils developed over shale materials are slightly acids and form the typical agricultural soils in the local area, parameters characterizing these soils are presented in Table 1.

Agricultural crops present in the area are mainly wheat and barley. Legume crops are not very common. Potatoes crops only represent roots, bulbs and tubers. 


\section{RADIONUCLIDES SELECTION}

In order to perform the study under actual conditions, the isotopes selected were ${ }^{238} \mathrm{U},{ }^{234} \mathrm{U},{ }^{230} \mathrm{Th}$ and ${ }^{226} \mathrm{Ra}$, belonging to the uranium series, and ${ }^{232} \mathrm{Th}$ and ${ }^{228} \mathrm{Th}$ from the thorium series. They have been chosen due to their presence in the mineralization of the old mine and due to their long half lifes. Radionuclides movement can be observed as tracers in the soils, plants, water and sediments present in the system.

Artificial radionuclides selected, has been ${ }^{36} \mathrm{Cl},{ }^{99} \mathrm{Tc}$ and ${ }^{233} \mathrm{U}$ and stable Iodine. These were selected because they have high importance in the contribution to the dose from the analysis of international exercises of assessment of HLW disposal [3].

\section{SAMPLING POINTS AND TYPE OF SAMPLES}

Two sets of samples have been selected. Local samples and samples from a reduced area of aprox. $3 \mathrm{~km}^{2}$ surrounding the mine.

Local samples taken are shown in Figure 1 (aprox scale 1:50000). A first field campaign was performed on June 1998. Four soil local samples were chosen (SU-1, SU-2, SU-3 and SU-4 in Figure 1), due to the different rock substrate types. Three lithologies are present in the area. Two sediment samples (SE-1 and SE-2 in Figure 1) and five water samples (A1, A2, A4, A5, A6 in Figure 1) were chosen. In the case of sediments, from the geographical point of view, and in the case of the water, to cover the main seasonal stream running in the area.

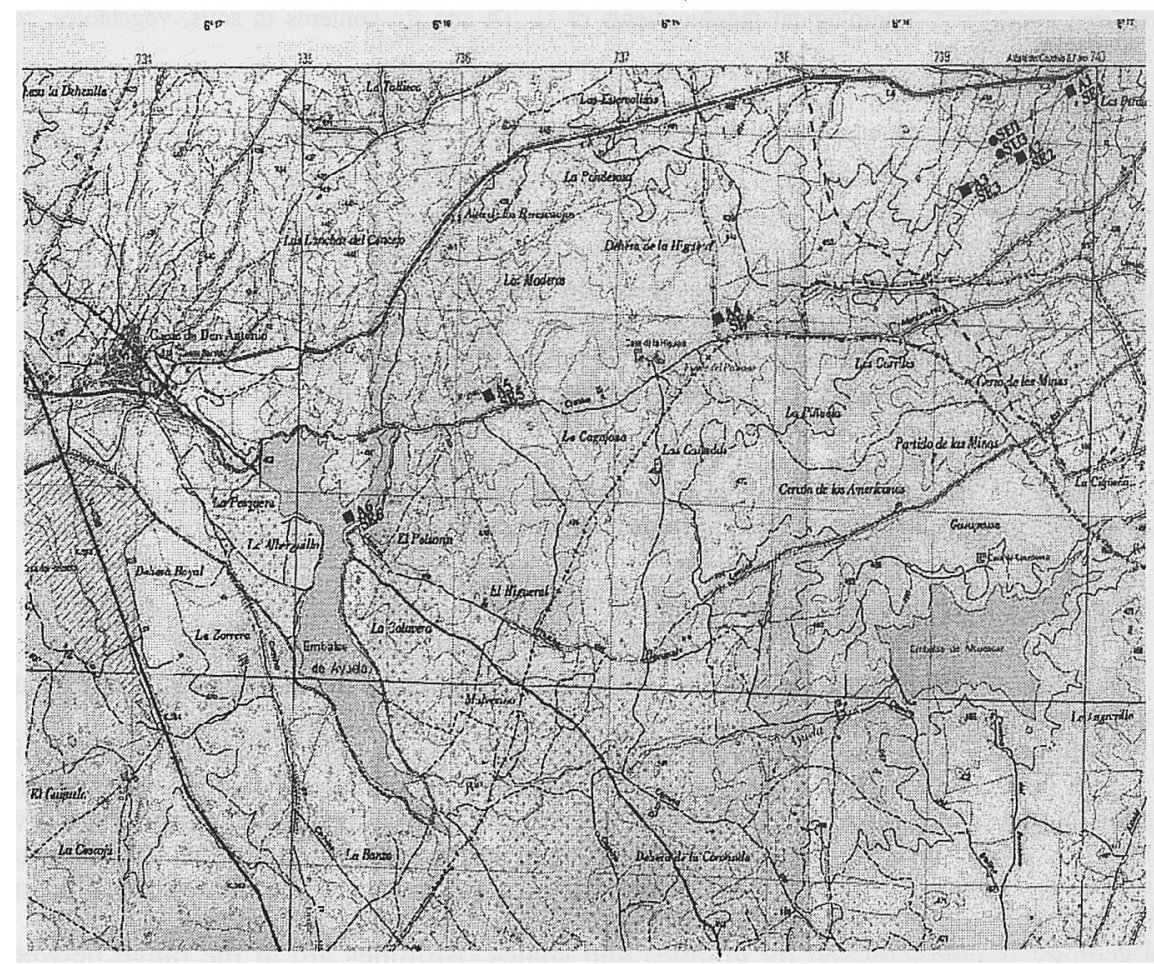

Legend of Figure 1:

Figure 1. Local sampling points

SE-1 and SE-2 Bed load sediments before and after the mine.

SU-1. Soil developed over porfiric granites

SU-2. Soil developed over shales

SU-3. Soil developed over alluvial sediments of the stream

SU-4. Soil developed over moscovite granites

$\mathrm{A} 1, \mathrm{~A} 2, \mathrm{~A} 4, \mathrm{~A} 5, \mathrm{~A} 6$ : Water and suspension load mass associated 
Experimental parameters measured for each local sample includes chemical composition, $\mathrm{pH}$, texture, bulk density and solid-liquid distribution coefficients for the artificial radionuclides. In the case of water and sediment samples, activity concentration of each isotope and load suspension mass in water has been determined, too.

Legend:

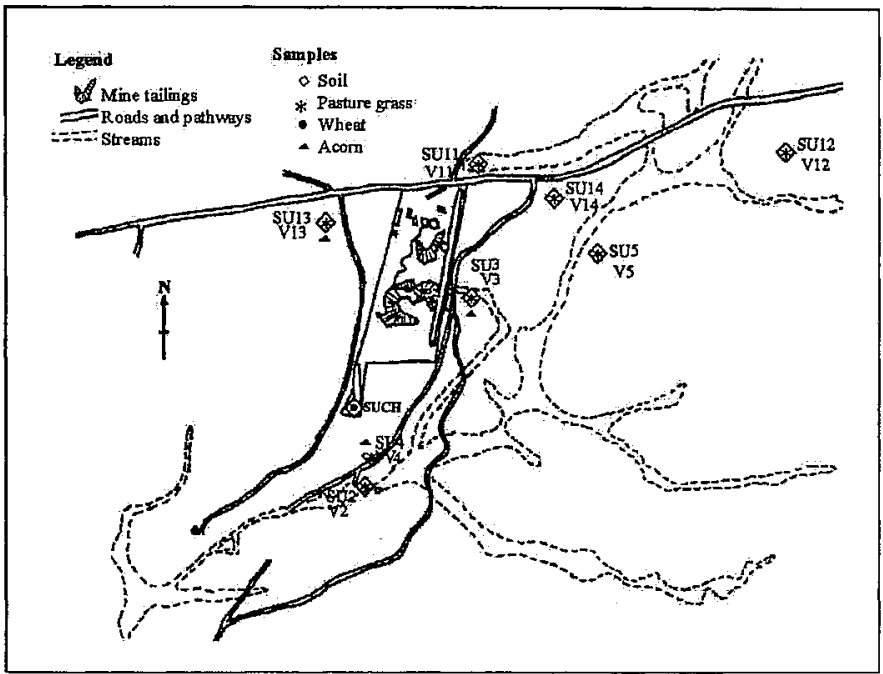

SU11+SU12+SU13+SU14= Composed sample soil SU1 over granites substrate.

SU2: Soil developed over terrace sediments of the main stream.

SU3 and SU4: Soils developed over granites substrate

SUCH: Soil developed over granites for wheat cultures

$\mathrm{V} 11+\mathrm{V} 12+\mathrm{V} 13+\mathrm{V} 14=$ Composed sample of pastures V1.

VCH: Winter wheat sample.

V13 and V4: Acorn samples.

Figure 2. Sampling points (approx. scale 1:8000) in the area surrounding the mine.

Samples taken in the reduced area surrounding the mine have been (see Figure 2$)^{1}$ soils ( 5 samples), associated pasture grasses (5 samples) and acoms ( 2 samples) from the Quercus rotundifolia trees growth on the soils selected. Four sampling campaigns were performed, during a one year period, considering the four seasons of the year. Soil and pasture samples were taken in June (representing medium precipitation and moderate-low temperatures), September (dry conditions with high temperatures), December (medium precipitation and medium-high temperatures) and April (high precipitation and low temperatures). Acorn samples were taken in September and December field campaigns.

One extra sampling point of soil (SCH, presented in Figure 2) was chosen to seed Winter Wheat, in the field and in a growth chamber in the laboratory, in order to obtain soil to plant transfer factors for the natural isotopes selected.

Experimental data obtained includes texture of soil, chemical composition of soils and vegetation samples, and activity concentrations of isotopes in soils and vegetation.

\section{MATERIALS AND METHODS}

For each soil location in the field, is disposed a square iron frame with an area of $0.25 \mathrm{~m}^{2}$. The cover vegetation, including roots, is taken, to obtain pasture samples. Soil is digged $10 \mathrm{~cm}$ depth and material is screening at a pore size of $2 \mathrm{~mm}$. using a steel sieve, collecting approximately $5 \mathrm{~kg}$. of samples. In the laboratory the soil material is screening to obtain particle size distribution of each sample, and radiochemical analysis is performed.

Vegetation samples (pasture grass and acorns) are washed in the laboratory, to remove particle soils adbered to the surface. They are dried and triturated to make the radiochemical analysis.

${ }^{1}$ Notation to distinguish samples is SU-X for local and SUX for the reduced area. 
Water samples were filtered (around $60 \mathrm{~L}$. of water per sample point) in situ and acidulated (to avoid precipitation of radionuclides in the recipient and development of organic material) with $3 \mathrm{~mL}$ concentration of $\mathrm{H}_{2} \mathrm{SO}_{4}$ per litre of sample. Sediment samples have been treated similarly to soil samples described above.

The radiochemical method for soil, sediment, water and vegetation samples, followed up to the preparation of the high-resolution alpha sources was based on the chemical separation of uranium and thorium by an anionic exchange resin [4] and the subsequent electrodeposition of the source [5].

Winter wheat (Triticum aestivum, Yecora variety) was seeded in situ (SUCH sample point in Figure 2). The seed was done on April and the harvest was done in September.

A total number of 8 pots filled with soil from SUCH point in Figure 2, $(40 \mathrm{~cm}$. depth and $20 \mathrm{~cm}$ diameter) were placed in a growth chamber in the laboratory. Daily cycles were programmed, temperature, moisture and sunlight. After five months (simulating meteorological conditions corresponding to December to April in a Mediterranean climate) the growth of the wheat plants was complete. The plants were irrigated during the three first months in order to simulate rainfall at the site.

For the wheat crop samples, the Environmental Radioactivity Laboratory of CIEMAT performed the radiochemical analyses for uranium, thorium and radium; following published analytical procedures [9, $10]$.

Experimental values of $K_{d}$ for the artificial isotopes has been obtained with the batch method, in the Laboratory of "Caracterización Hidrogeoquímica de Emplazamientos" of CIEMAT [13]. The determination have been done with a low solid/liquid relation $(1 / 10)$ to obtain measurements under realistic environmental conditions. Three determinations have been obtained for each sample.

\section{PARAMETER VALUES OBTAINED FOR SOLID-LIQUID DISTRIBUTION COEFFICIENTS FROM EXPERIMENTAL AND EMPIRICAL METHODS}

\subsection{Experimental method}

The physical characterization of soils and sediments to analyse its sorption properties, is presented in Table 1 for the local samples. Bulk density has been determined from two measurements of each sampling point. Texture have been obtained from the mean of tree determinations.

Table 1. Physical characterization of the local soil and sediment samples

\begin{tabular}{|c|c|c|c|c|c|c|c|}
\hline & & \multicolumn{3}{|c|}{ SOILS } & \multicolumn{2}{c|}{ SEDIMENTS } \\
\hline Substrate type & & Porfiric Granite & Shales & Alluvial & Moscovite Granite & & \\
\hline & Sampling Point & SU 1 & SU 2 & SU 3 & SU 4 & SE I & SE2 \\
\hline Bulk dens. & $\left(\mathrm{Kg} \mathrm{m}^{-3}\right)$ & 2680 & 2740 & 2650 & 2690 & 2710 & 2720 \\
\hline Texture & & Loamy & Loamy & Sandy & Sandy & Sandy & Sandy \\
\hline
\end{tabular}

$\mathrm{K}_{\mathrm{d}}$ values given in the following tables, for the local samples, corresponds with the average of three experimental determinations. Here are shown results for technetium and uranium.

$\mathrm{K}_{\mathrm{d}}$ values for ${ }^{99} \mathrm{Tc}\left(\mathrm{TcO}_{4}^{-}\right)$are shown in Table 2. These are low (order of $10^{-3} \mathrm{~m}^{3} \mathrm{~kg}^{-1}$ ) except for sampling point SE-2, that is one order higher, but inside the literature ranges [9].

Table $2 \mathrm{~K}_{\mathrm{d}}$ experimental values for technetium $\left(7.35 \cdot 10^{-7} \mathrm{M}=0.073 \mathrm{mg} / \mathrm{L}\right)$

\begin{tabular}{|c|c|c|c|c|c|}
\hline $\begin{array}{c}\text { Sampling } \\
\text { point }\end{array}$ & $\begin{array}{c}\text { Initial } \\
\mathrm{pH}\end{array}$ & $\begin{array}{c}\text { Final } \\
\mathrm{pH}(14 \mathrm{~d})\end{array}$ & $\begin{array}{c}\mathrm{K}_{\mathrm{d}} \\
\left(\mathrm{m}^{3} / \mathrm{kg}\right)\end{array}$ & $\sigma$ & $\begin{array}{c}\text { (IAEA, 1994) } \\
\text { Range }\end{array}$ \\
\hline SU-1 & 6,9 & 6,99 & $6,4 \times 10^{-4}$ & $0,5 \times 10^{-5}$ & $\begin{array}{c}1.1 \mathrm{E}-5-9 . \mathrm{E}- \\
2\end{array}$ \\
\hline SU-2 & 6,71 & 6,98 & $8,9 \times 10^{-4}$ & $1,0 \times 10^{-4}$ & $\begin{array}{c}1.1 \mathrm{E}-5-9 . \mathrm{E}- \\
2\end{array}$ \\
\hline SU-3 & 7,36 & 7,11 & $5,2 \times 10^{-4}$ & $0,5 \times 10^{-5}$ & $\begin{array}{c}3.7 \mathrm{E}-6-5 . \mathrm{E}- \\
3\end{array}$ \\
\hline SU-4 & 7,54 & 7,3 & $6,0 \times 10^{-4}$ & $0,7 \times 10^{-5}$ & $\begin{array}{c}3.7 \mathrm{E}-6-5 . \mathrm{E}- \\
3\end{array}$ \\
\hline SE-1 & 7,65 & 7,27 & $4,9 \times 10^{-4}$ & $0,3 \times 10^{-5}$ & $0.0-1 . \mathrm{E}-1$ \\
\hline SE-2 & 7,75 & 7,29 & $5,45 \times 10^{-3}$ & $2,0 \times 10^{-4}$ & $0.0-1 . \mathrm{E}-1$ \\
\hline
\end{tabular}

Table 3 shows $\mathrm{K}_{4}$ values obtained for uranium $\left(\mathrm{UO}_{2}{ }^{2+}\right)$. Two different concentrations of ${ }^{233} \mathrm{U}$ $\left(2.11 \times 10^{-6}\right.$ and $\left.4.45 \times 10^{-4} \mathrm{M}\right)$ have been used due to results obtained for the first and higher concentration, 
that shows a big dispersion between samples. To avoid complexes formation or solute precipitation a lower concentration was then used.

Table 3. Experimental $\mathrm{K}_{d}$ values obtained for two initial activity concentrations of ${ }^{233} \mathrm{U}$.

\begin{tabular}{|c|c|c|c|c|c|c|c|c|c|}
\hline & \multicolumn{4}{|c|}{$\mathrm{U}-233\left(2.11 \cdot 10^{-6} \mathrm{M}=0.492 \mathrm{mg} / \mathrm{L}\right)$} & \multicolumn{4}{|c|}{$\mathrm{U}-233\left(4.45 \cdot 10^{-7} \mathrm{M}=0.104 \mathrm{mg} / \mathrm{L}\right)$} & \\
\hline $\begin{array}{c}\text { Sampling } \\
\text { point }\end{array}$ & $\begin{array}{c}\text { Initial } \\
\mathrm{pH}\end{array}$ & $\begin{array}{c}\text { Final } \\
\mathrm{pH}(14 \mathrm{~d})\end{array}$ & $\mathrm{K}_{\mathrm{d}}\left(\mathrm{m}^{3} / \mathrm{kg}\right)$ & $\sigma$ & $\begin{array}{c}\text { Initial } \\
\mathrm{pH}\end{array}$ & $\begin{array}{c}\text { Final } \\
\mathrm{pH}(14 \mathrm{~d})\end{array}$ & $\mathrm{K}_{\mathrm{d}}\left(\mathrm{m}^{3} / \mathrm{kg}\right)$ & $\sigma$ & $\begin{array}{c}\text { (IAEA, 1994) } \\
\text { Range }\end{array}$ \\
\hline SU-1 & 6,64 & 6,81 & 2,069 & 0,119 & 6,8 & 7,68 & 1,183 & 0,116 & $5.5 \mathrm{E}-5-20$ \\
\hline SU-2 & 6,47 & 7,11 & 2,505 & 0,094 & 6,77 & 7,85 & 1,432 & 0,154 & $5.5 \mathrm{E}-5-20$ \\
\hline SU-3 & 6,98 & 7,47 & 0,634 & 0,020 & 7,34 & 8,38 & 0,438 & 0,043 & $1.7 \mathrm{E}-5-9.0$ \\
\hline SU-4 & 7,07 & 7,62 & 0,386 & 0,007 & 7,46 & 7,98 & 0,338 & 0,020 & $1.7 \mathrm{E}-5-9.0$ \\
\hline SE-1 & 7,18 & 7,38 & $7,3 \times 10^{-2}$ & $4 \times 10^{-4}$ & 7,66 & 7,94 & $7,7 \times 10^{-2}$ & $7,6 \times 10^{-3}$ & 2.E-2 -1.0 \\
\hline SE-2 & 7,38 & 7,63 & $3,6 \times 10^{-2}$ & $4 \times 10^{-4}$ & 7,6 & 8,02 & $3,7 \times 10^{-2}$ & $2,5 \times 10^{-3}$ & 2.E-2 - 1.0 \\
\hline
\end{tabular}

${ }^{233} \mathrm{U}$ has been added as uranile nitrate, but the evolution of $\mathrm{pH}$ is in both cases towards more basic values.

Experimental results shown high sorption in general, but there is a clear difference among type of samples (soils and sediments). Loamy soils (SU-1 and SU-2) show a higher sorption as it is referred in the literature [9]. Sandy soils (SU-3 and SU-4) show a lower sorption as could be expected. For sediments, values obtained fit to the typical range [9].

To explain these variations, the chemical composition of the soils and sediments have been correlated with the experimental $\mathrm{K}_{d}$ values obtained. For example, it is observed in Figure 3 a strong dependency of $\mathrm{K}_{d}$ value with the iron content $\left(\mathrm{Fe}_{2} \mathrm{O}_{3}\right)$ up to around $1.8 \%$ and, a slight dependency for higher iron content.

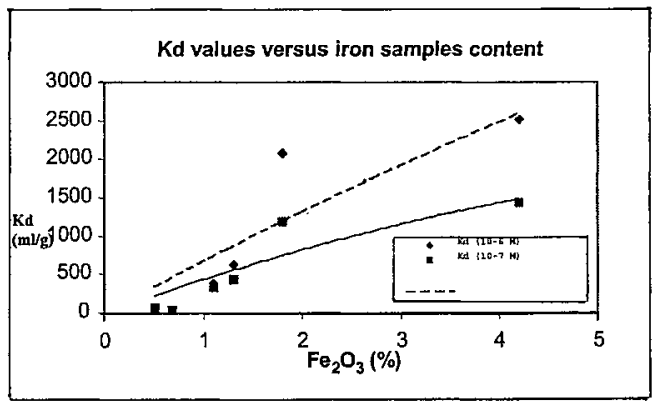

Figure 3. Relation $\mathrm{K}_{\mathrm{d}}$ vs. Iron content of the soils and sediments regional samples.

It is observed the same tendency in both cases of uranium initial activity concentrations, although values are lower for the lower concentration indicating that increasing the tracer concentration all the possible sites for sorption are occupied.

\subsection{Empirical method}

From experimental basis, [10] have proposed an empirical approach to calculate $\mathrm{K}_{\mathrm{d}}$ for radionuclides from the soil to plant transfer factors (TF) measured, on the basis of the strong correlation between $\mathrm{TF}$ and $\mathrm{K}_{\mathrm{d}}$, following the equation: $\ln K_{d}=a+b(\ln T F)$, Where $a$ is a constant and depends on the soil texture and $b$ is equal to -0.5 .

Texture of soils of the biospheric area surrounding the mine, have been obtained. Soil to plant transfer factors mean values have been obtained from the measured concentrations in pasture and soils, of uranium, thorium and radium, from the four field sampling made. Distribution coefficients estimated from the above equation and experimental soil to plant transfer factors used, are shown in Table 4. 
Table 4. Uranium, thorium and radium $\mathrm{K}_{\mathrm{d}}$ values estimated from the empirical method.

\begin{tabular}{|c|c|c|c|c|c|c|c|}
\hline $\begin{array}{c}\text { Sampling } \\
\text { point }\end{array}$ & Texture & $\begin{array}{c}\text { Experimenta } \\
1 \\
\text { Uranium TF }\end{array}$ & $\begin{array}{c}\mathrm{K}_{\mathrm{d}}\left(\mathrm{m}^{3} / \mathrm{kg}\right) \\
\text { Uranium }\end{array}$ & $\begin{array}{c}\text { Experimental } \\
\text { Thorium TF }\end{array}$ & $\begin{array}{c}\mathrm{K}_{\mathrm{d}} \\
\left(\mathrm{m}^{3} / \mathrm{kg}\right) \\
\text { Thorium }\end{array}$ & $\begin{array}{c}\text { Experimental } \\
\text { Radium TF }\end{array}$ & $\begin{array}{c}\mathrm{K}_{\mathrm{d}}\left(\mathrm{m}^{3} / \mathrm{kg}\right) \\
\text { Radium }\end{array}$ \\
\hline SU1 & Sandy & $8,472 \mathrm{E}-02$ & $2,834 \mathrm{E}-02$ & $1,623 \mathrm{E}-01$ & $2,048 \mathrm{E}-02$ & $1,333 \mathrm{E}-01$ & $2,259 \mathrm{E}-02$ \\
\hline SU2 & Loamy & $1,038 \mathrm{E}-01$ & $8,934 \mathrm{E}-02$ & $1,473 \mathrm{E}-01$ & $7,502 \mathrm{E}-02$ & $1,414 \mathrm{E}-01$ & $7,657 \mathrm{E}-02$ \\
\hline SU3 & Loamy & $1,179 \mathrm{E}-01$ & $8,383 \mathrm{E}-02$ & $4,636 \mathrm{E}-02$ & $1,337 \mathrm{E}-01$ & $2,780 \mathrm{E}-01$ & $5,461 \mathrm{E}-02$ \\
\hline SU4 & Sandy & $9,371 \mathrm{E}-02$ & $2,694 \mathrm{E}-02$ & $2,934 \mathrm{E}-01$ & $1,523 \mathrm{E}-02$ & $1,300 \mathrm{E}-01$ & $2,288 \mathrm{E}-02$ \\
\hline SU5 & Loamy & $7,372 \mathrm{E}-02$ & $1,060 \mathrm{E}-01$ & $7,483 \mathrm{E}-02$ & $1,052 \mathrm{E}-01$ & $2,602 \mathrm{E}-01$ & $5,644 \mathrm{E}-02$ \\
\hline
\end{tabular}

Value ranges obtained from the literature [9] for sandy soils for uranium (1.7E-05 - 9.0), thorium $(4.5 \mathrm{E}-02-2.0 \mathrm{E}+02)$ and radium $(8.2 \mathrm{E}-4-3.0 \mathrm{E}+02)$. For loamy soils and uranium $(5.5 \mathrm{E}-05-2.0 \mathrm{E}+01)$, thorium (3.3) and radium (7.4E-02 - 1.8E+04).

\section{CONCLUSIONS}

$\mathrm{K}_{\mathrm{d}}$ values obtained from the batch method, for technetium in soils and sediments local samples shown low sorption behaviour, this is according to literature data. On the other hand $\mathrm{K}_{\mathrm{d}}$ values obtained for uranium-233, shown high sorption values, with clear dependency of type of sampled soil and iron content of the sample.

Empirical values estimated for solid-liquid distribution coefficients are not comparable directly with experimental values obtained, because the measurements have been made on different soil samples. In any case estimated $K_{d}$ values are one or two orders of magnitude lower than experimental ones and are more close to the central distribution values of literature range.

$\mathrm{K}_{\mathrm{d}}$ parameter values and other characteristic parameters (texture, density, moisture content, mass suspension load, organic matter content, soil to plant transfer factors), obtained from the study will be considered for the uncertainty analysis in Performance Assessment exercises to be performed in the future.

\section{Acknowledgments}

The authors are grateful to Empresa Nacional de Residuos Radiactivos (ENRESA) for financial support.

\section{References}

1. Trewartha. An Introduction to Climate. $4^{\text {th }}$ Edtition, McGraw Hill (1968).

2. United States Soil Survey Staff (USDA), Soil Taxonomy. A Basic System of Soil Classification for Making and Interpreting Soil Survey. Agriculture Handbook. (1975)

3. Pinedo, P. and Agüero, A. Contribuyentes principales a la dosis potencial debida a almacenamientos geológicos profundos. Radioprotección. SEPR, (2000). $N^{\circ}$ Extraordinario Septiembre. pp. 56-58.

4. Vera Tomé, F., Jurado Vargas, M. \& Martín Sánchez, A. Yields and losses at each step in preparing uranium and thorium samples for alpha spectrometry. Applied Radiation and Isotopes, 45, (1994) pp. 449-452.

5. Vera Tomé, F., Jurado Vargas, M. \& Martín Sánchez, A. SIMPLEX method for optimization of experiments. Application to electrodeposition in alpha spectrometry. Nuclear Instruments and Methods in Physics Research, A348, . (1994) pp.183-187.

6. CIEMAT PR-X2-01. Procedimiento para la determinación de ${ }^{230} \mathrm{Th}$ en suelos. (1994).

7. CIEMAT-PR-X2-09, Procedimiento para la separación radioquímica y determinación, mediante espectrometría alfa, de uranio en aguas, suelos, sedimentos y muestras biológicas. (1996).

8. Hernández Benítez, A. I. Resultados de las determinaciones de parámetros de sorción realizadas en muestras del proyecto BIOREFS. Octubre 1999. CIEMAT internal report.

9. IAEA. Handbook of parameter values for the prediction of radionuclide transfer in temperate environment. Technical Report Series n1 364. (1994). Vienna

10. Sheppard, M. I \& Thibault, D. H. Default soil solid/liquid partition coefficients, Kds, for four major soil types: A compendium. Health Physics, 59, (1990) pp. 471-482. 